\title{
Proteins related to lipoprotein profile were identified using a pharmaco-proteomic approach as markers for growth response to growth hormone (GH) treatment in short prepubertal children Björn Andersson*1, Gunnel Hellgren'1, Andreas FM Nierop ${ }^{2}$, Ze'ev Hochberg ${ }^{3}$ and Kerstin Albertsson-Wikland ${ }^{1}$
}

\author{
Address: ${ }^{1}$ Göteborg Pediatric Growth Research Center, Department of Pediatrics, Institute of Clinical Sciences, Sahlgrenska Academy, University \\ of Gothenburg, Sweden, ${ }^{2}$ Muvara bv, Leiderdorp, The Netherlands and ${ }^{3}$ Meyer Children's Hospital, Rambam Medical Center and Rappaport \\ Faculty of Medicine and Research Institute, Technion - Israel Institute of Technology, Haifa, Israel \\ Email: Björn Andersson* - bjorn.k.andersson@vgregion.se; Gunnel Hellgren - gunnel.hellgren@vgregion.se; \\ Andreas FM Nierop - nierop@muvara.nl; Ze'ev Hochberg - z_hochberg@rambam.health.gov.il; Kerstin Albertsson-Wikland - kerstin.albertsson- \\ wikland@pediat.gu.se \\ * Corresponding author
}

Published: 2 November 2009

Proteome Science 2009, 7:40 doi:10.1/86/1477-5956-7-40

This article is available from: http://www.proteomesci.com/content/7///40

(c) 2009 Andersson et al; licensee BioMed Central Ltd.

This is an Open Access article distributed under the terms of the Creative Commons Attribution License (http://creativecommons.org/licenses/by/2.0), which permits unrestricted use, distribution, and reproduction in any medium, provided the original work is properly cited.

\begin{abstract}
Background: The broad range in growth observed in response to growth hormone (GH) treatment is mainly caused by individual variations in both $\mathrm{GH}$ secretion and $\mathrm{GH}$ sensitivity. Individual $\mathrm{GH}$ responsiveness can be estimated using evidence-based models that predict the response to GH treatment; however, these models can be improved. Highthroughput proteomics techniques can be used to identify proteins that may potentially be used as variables in such models in order to improve their predictive ability. Previously we have reported that proteomic analyses can identify biomarkers that discriminate between short prepubertal children with idiopathic short stature (ISS) who show good or poor growth in response to $\mathrm{GH}$ treatment. In this study we used a pharmaco-proteomic approach to identify novel factors that correlate with the growth response to $\mathrm{GH}$ treatment in prepubertal children who are short due to $\mathrm{GH}$ deficiency or ISS. The study included 128 short prepubertal children receiving $\mathrm{GH}$ treatment, of whom 39 were $\mathrm{GH}$ deficient and 89 had ISS. Serum protein expression profiles at study start and after I year of GH treatment were analyzed using SELDI-TOF. Cross-validated regression and random permutation analyses were performed to identify significant correlations between protein expression patterns and the 2-year growth response to $\mathrm{GH}$ treatment.
\end{abstract}

Results: At start of treatment we identified a combination of seven protein peaks that correlated with the 2-year growth response in the $\mathrm{GH}$-deficient group $\left(\mathrm{R}^{2}=0.73\right)$. After I year of treatment, a combination of four peaks in the $\mathrm{GH}$ deficient group $\left(R^{2}=0.64\right)$, eight peaks in the ISS group $\left.R^{2}=0.47\right)$ and eight peaks in the total study group correlated with the 2-year growth response $R^{2}=0.38$ ).

The peaks identified corresponded to apolipoproteins A-I, A-II, C-I, C-III, transthyretin and serum amyloid A 4, which are all part of the high-density lipoprotein. 
Conclusion: Using a proteomic approach we identified biomarkers related to the lipoprotein profile that could be used to predict growth response to $\mathrm{GH}$ treatment in prepubertal children who are short as a result of $\mathrm{GH}$-deficiency or who have ISS.

These results support our previous findings that apolipoproteins and transthyretin may have a role in GH sensitivity.

\section{Background}

Growth during childhood depends, among other things, on the balance between the level of endogenously secreted growth hormone $(\mathrm{GH})$ and the responsiveness of the target tissue to GH. Furthermore, a broad range of serum GH levels has been observed in children with similar growth rates [1] and it is known that GH exerts its stimulatory effect on growth in children during childhood in a dose-dependent way [2]. There is also considerable intra-individual variability in growth in response to $\mathrm{GH}$ treatment among children who are GH-deficient and among those who have idiopathic short stature (ISS) [3$6]$. To deal with this complexity, we and others have constructed evidence-based models for predicting growth in response to $\mathrm{GH}$ treatment [7-11]. These models provide an indirect measurement of individual responsiveness to GH [12]. The best models available today explain up to $80 \%$ of the growth in response to GH. Early growth data, auxological data of the child and the parents and the level of spontaneous GH secretion over 24 h are important variables in these models [7-11]. Because some of these parameters, such as early growth data and parental auxological data, are not always readily available, there is a need to develop a model that includes only parameters that can be obtained at the start of the growth investigation at the pediatric unit. To achieve this it is necessary to change the focus from single marker studies toward a broader search for multiple markers of growth response using high-throughput techniques.

We have previously used surface-enhanced laser desorption/ionization time-of-flight mass spectrometry (SELDITOF MS) to identify biomarkers that discriminate between good and poor responders to GH treatment among a group of children with ISS [13]. We showed that information on the change in peak intensities of apolipoprotein (Apo) A-II and transthyretin (TTR) during the first year of GH treatment could be used to correct classify $82 \%$ of children receiving $\mathrm{GH}$ as good or poor treatment responders, respectively [13].

In this study we used the same technique to search for biomarkers that correlated with growth response to $\mathrm{GH}$ treatment in short prepubertal children, who were either GH-deficient or of ISS. Serum samples taken at the start of a clinical trial of GH and after 1 year of treatment from children with a broad range of levels of GH secretion at start were analyzed. We found that serum markers related to nutrition and fat transport in the body correlated with the 2-year growth response.

\section{Subjects and Methods Ethical consideration}

The protocol was approved by the ethical boards of the Universities of Gothenburg (for patients from Gothenburg and Halmstad), Umeå, Uppsala and Malmö and the Medical Product Agency of Sweden. Written informed consent was obtained from all parents and from children if old enough. The trial was performed in accordance with the Declaration of Helsinki and Good Clinical Practice guidelines.

\section{Study population}

The per-protocol study population from the GH dose clinical trial (TRN 98-0198-003) consists of 128 short prepubertal children of Caucasian origin receiving $\mathrm{GH}$ treatment; see [5] for more detailed information. Study patients were randomized either to a group receiving an individualized (two-thirds of patients) or a standard GH dose (one-third of patients). The standard GH dose was $43 \mu \mathrm{g} / \mathrm{kg} /$ day. The individualized GH dose comprised one of six different doses (mean 49 , range $17-100 \mu \mathrm{g} / \mathrm{kg} /$ day), calculated using a prediction model that considered estimated GH sensitivity and the difference between the current height of the child and mid-parental height (MPH), as previously described [12].

The maximum peak GH secretion $\left(\mathrm{GH}_{\max }\right) \geq 32 \mathrm{mU} / \mathrm{L}$ on an arginine-insulin tolerance test (AITT) or of the spontaneous GH secretion over a 24 h period was used to classify the patients as having either ISS $(n=89)$ or short stature due to GH deficiency $(n=39)$. Clinical data for the patient groups are presented in Table 1.

\section{Study design}

Fasting blood samples were taken at the start of the study and after 1 year on GH treatment. Samples were stored at $-70^{\circ} \mathrm{C}$ and were not thawed until the time of analysis. No sample was stored for more than 8 years before analysis.

\section{Hormone evaluation}

Published reference values were used to assess the results of analyses of GH [14], insulin-like growth factor I (IGF-I) [15] and IGF-binding protein 3 (IGFBP-3) [16], which 
Table I: Auxiological data for the study groups

\begin{tabular}{|c|c|c|c|c|c|c|c|c|c|}
\hline \multicolumn{4}{|c|}{ A) Total group ( $n=128 ; 38$ girls, 90 boys) } & \multicolumn{3}{|c|}{ B) ISS ( $n=89,25$ girls, 64 boys) } & \multicolumn{3}{|c|}{ C) GHD ( $n=39,13$ girls, 26 boys) } \\
\hline Variables & Median & Min & Max & Median & Min & Max & Median & Min & Max \\
\hline \multicolumn{10}{|l|}{ At birth } \\
\hline Gestational age (weeks) & 39 & 33 & 42 & 39 & 33 & 42 & 39 & 36 & 42 \\
\hline Height SDS & $-0,66$ & $-2,52$ & 1,68 & $-0,74$ & $-2,52$ & 1,68 & $-0,70$ & $-2,52$ & 1,68 \\
\hline \multicolumn{10}{|l|}{ At GH start } \\
\hline Age (yrs) & 7,27 & 3,05 & 10,95 & 7,32 & 3,24 & 10,95 & 7,14 & 3,05 & 10,94 \\
\hline Height SDS & $-2,64$ & $-4,10$ & $-1,77$ & $-2,64$ & $-4,10$ & $-1,77$ & $-2,59$ & $-3,65$ & $-1,98$ \\
\hline Weight SDS & $-2,24$ & $-4,31$ & 0,26 & $-2,39$ & $-4,31$ & $-0,45$ & $-2,03$ & $-3,80$ & 0,26 \\
\hline BMI SDS & $-0,47$ & $-3,35$ & 2,11 & $-0,55$ & $-3,35$ & 1,88 & $-0,20$ & $-1,80$ & 2,11 \\
\hline $\mathrm{GH}_{\max } \mathrm{AITT}(\mathrm{mU} / \mathrm{L})$ & 16,95 & 1,10 & 62,90 & 19,60 & 1,10 & 62,90 & 15,10 & 1,60 & 22,30 \\
\hline $\mathrm{GH}_{\max } 24 \mathrm{~h}(\mathrm{mU} / \mathrm{L})$ & 24,85 & 0,80 & 58,10 & 28,10 & 12,70 & 58,10 & 14,70 & 0,80 & 22,10 \\
\hline Diff MPHSDS & $-1,73$ & $-3,53$ & $-0,61$ & $-1,72$ & $-3,53$ & $-0,61$ & $-1,77$ & $-2,45$ & $-0,78$ \\
\hline HDL (mg/L) & $\mathrm{I}, 44$ & 0,64 & 2,70 & $\mathrm{I}, 44$ & 0,64 & 2,70 & $\mathrm{I}, 44$ & 0,91 & 2,24 \\
\hline IGF-I SDS & $-1,10$ & $-5,17$ & 2,25 & $-1,19$ & $-3,84$ & 2,25 & $-1,06$ & $-5,17$ & 0,91 \\
\hline GH dose $(\mu g / k g /$ day $)$ & 44,20 & 17,00 & 102,00 & 44,20 & 17,00 & 102,00 & 44,20 & 17,00 & 68,00 \\
\hline \multicolumn{10}{|l|}{ After 2 yrs of treatment } \\
\hline Height SDS & $-1,45$ & $-3,00$ & 0,20 & $-1,45$ & $-3,00$ & 0,20 & $-1,45$ & $-2,42$ & 0,05 \\
\hline Delta height SDS 2 yrs & 1,26 & 0,23 & 2,69 & 1,22 & 0,23 & 2,69 & 1,31 & 0,51 & 2,39 \\
\hline BMI SDS & $-0,24$ & $-3,10$ & 2,03 & $-0,05$ & $-3,10$ & 1,88 & $-0,08$ & $-2,14$ & 2,03 \\
\hline HDL (mg/L) & 1,36 & 0,76 & 2,06 & 1,37 & 0,76 & 2,06 & 1,28 & 0,94 & 1,97 \\
\hline IGF-I SDS & $\mathrm{I}, 57$ & $-1,48$ & 4,21 & 1,49 & $-0,65$ & 3,82 & 1,57 & $-1,48$ & 4,21 \\
\hline
\end{tabular}

AITT, arginine--insulin tolerance test; $\mathrm{GH}_{\text {max }}$, maximum peak of $\mathrm{GH}$ secretion; IGF-I, insulin-like growth factor I; GHD, GH deficient; $\mathrm{MPH}$, midparental height; diffMPHSDS, difference in height SDS of the child versus its mid-parental height SDS

$0.1 \cup \mathrm{GH} / \mathrm{kg} /$ day $=33 \mu \mathrm{g} / \mathrm{kg} /$ day

The reference values used for SDS calculations were obtained from [18] for height and weight and [I5] for IGF-I.

were performed at the GP-GRC laboratory (Swedac accredited no 1899) at the University of Gothenburg. High-density lipoprotein (HDL) was measured at the Department of Clinical Chemistry, Sahlgrenska University Hospital (accredited according to the international standard ISO/IEC 17025).

\section{Growth evaluation}

The childhood component [17] of the Swedish population-based growth reference values was used for the height-related inclusion criteria and to express the height, weight [18] and body mass index [19] of the patients and their parents. Reference standards of newborns were used for standard deviation score (SDS) at birth [20]. 


\section{Surface-enhanced laser desorption/lonization time-of- flight mass spectrometry (SELDI-TOF MS) serum protein profiling}

Serum samples were thawed, denatured and fractionated using anion-exchange beads in a serum fractionation kit (Bio-Rad Laboratories, Hercules, CA) according to protocols provided by Bio-Rad Laboratories. Based on results from a previous study [13], serum fraction 5 and 6 (pH 3 and organic solvent) were analyzed together using weak anion-exchange (CM10) arrays, fraction 1 (flow through) was analyzed by immobilized metal-affinity capture (IMAC30) arrays and fraction 4 (pH 4) was analyzed using reversed-phase (H50) arrays. CM10 arrays were equilibrated twice with $150 \mu \mathrm{l}$ binding buffer $(100 \mathrm{mM}$ NaAcetate, $\mathrm{pH} 4.0$ ). IMAC30 arrays were charged using 50 $\mu \mathrm{l} 0.1 \mathrm{M}$ CuSO $4,10 \mathrm{~min}$, washed with $150 \mu \mathrm{H} \mathrm{H}_{2} \mathrm{O}, 1 \mathrm{~min}$, neutralized with $150 \mu \mathrm{l} 0.1 \mathrm{M} \mathrm{NaAc} \mathrm{pH}$ 4.0, $5 \mathrm{~min}$, washed with $150 \mu \mathrm{H} \mathrm{H}_{2} \mathrm{O}, 1$ min, equilibrated twice with $150 \mu \mathrm{l}$ binding buffer $(0.1 \mathrm{M} \mathrm{Na} 3 \mathrm{PO} 4,0.5 \mathrm{M} \mathrm{NaCl}, \mathrm{pH}$ 7.0). H50 arrays were washed with $200 \mu \mathrm{l} \mathrm{50 \%}$ acetonitrile (ACN) (Merck, Darmstadt, Germany) $2 \times 5$ min, equilibrated twice with $150 \mu \mathrm{l}$ binding buffer $(10 \% \mathrm{ACN}$, $0.1 \%$ trifluoroacetic acid (Merck)). After equilibration, a $10 \mu \mathrm{l}$ sample and $90 \mu \mathrm{l}$ binding buffer were applied to duplicate samples on the arrays and mixed at room temperature using a DPC MicroMix 4 for $1 \mathrm{~h}$ (CM10 and IMAC30) or $1.5 \mathrm{~h}$ (H50). After protein binding, the arrays were washed three times with $150 \mu \mathrm{l}$ binding buffer, rinsed twice with $150 \mu \mathrm{l} 1 \mathrm{mM}$ HEPES, and air-dried. Afterwards, $0.6 \mu \mathrm{l}$ of a $50 \%$ solution of sinapinic acid (SPA) (Bio-Rad Laboratories) in $0.5 \%$ trifluoroacetic acid and $50 \% \mathrm{ACN}$ were applied twice to each spot as a matrix.

Time-of-flight spectra were generated using a PBS IIc ProteinChip reader (Bio-Rad Laboratories). Instrument settings for the analysis were optimized in the mass range of 2.3-20.0 kDa and data were averaged from 180 transients for each protocol. To minimize experimental variation, all samples were randomized and analyzed concurrently within 1 week by the same operator. In addition, one reference serum sample was randomly applied on each array and evaluated. The mass accuracy was calibrated in the molecular range of 5-18 $\mathrm{kDa}$ using external calibrators from Bio-Rad Laboratories. The same calibration equation was used for all samples.

\section{Data preprocessing}

Data handling was performed using ProteinChip Data Manager (Bio-Rad Laboratories). All spectra were baseline-subtracted and normalized according to total ion current. Settings for peak identification and clustering of peaks across multiple spectra were first pass signal-tonoise ratio $(\mathrm{S} / \mathrm{N})>3$ in $15 \%$ of all spectra and second pass $\mathrm{S} / \mathrm{N}>2$, with a cluster mass window of $0.3 \%$ of the mass.
Spectra were visually inspected and patients were excluded from further data analysis if profiles clearly differed between the duplicate samples or if the overall quality was low in one or both of the spectra (i.e. high noise, overall low peak intensity or an abnormal normalization factor in combination with visually deviating spectra). This process resulted in the identification of 147 valid peaks for CM10 $(\mathrm{n}=67)$, IMAC30 $(\mathrm{n}=46)$ and $\mathrm{H} 50(\mathrm{n}=$ $34)$ in the mass/charge $(\mathrm{m} / \mathrm{z})$ area between 2.3 and 30.0 $\mathrm{kDa}$. The average coefficient of variations $(\mathrm{CV})$ for the peaks detected in all of the reference samples was 30.1\% for CM10, 34.1\% for IMAC30 and 32.8\% for H50.

Only patients for whom there were two high-quality mass spectra for the relevant array and time point were included in further statistical analysis. This resulted in a study population of 128 children for the CM10 analyses at all time points. For analyses of peak data from the three different arrays merged together, the study populations were 121 children at the start of the study, 124 children after 1 year and 120 children for the change between baseline and 1 year (delta $0-1$ year).

\section{Protein identification}

ACN precipitation was performed, as previously described [21], on the pooled fraction 5 and 6 to remove high molecular weight proteins. The precipitate was subjected to SDS page and Coomassie blue staining to visualize the proteins. The protein bands with molecular weights corresponding to the biomarkers of interest were cut out and passive elution was performed. First the excized gel pieces were washed with $50 \% \mathrm{ACN} / 50 \mathrm{mM}$ Ambic for $3 \times 15$ min or until the gel pieces were destained. The gel pieces were dehydrated with $100 \% \mathrm{ACN}$, heated to $50^{\circ} \mathrm{C}$ for 5 min and thereafter dried in a Speed-Vac. $100 \mu \mathrm{l}$ of $45 \%$ formic acid, 30\% ACN and 10\% isopropanol was added. The tubes were sonicated for $30 \mathrm{~min}$ in a water bath at room temperature and incubated at room temperature for approximately $4 \mathrm{~h}$. One microliter of each sample was analyzed on a NP20 ProteinChip array with saturated SPA. The remainder of the sample obtained from passive elution was incubated overnight and sonicated the next morning. Each supernatant was transferred to a new tube and dried in a Speed-Vac. Depletion experiments and ingel digestions were performed as previously described [13]. Protein identification by nanoflow LC-MS/MS was performed on a hybrid linear ion-trap Fourier transform ion cyclotron resonance (FTICR) mass spectrometer (LTQ-FT, Thermo Electron, Bremen, Germany), as previously described [13].

\section{Statistics}

For all analyses the 2-year growth response (delta height SDS 0-2 years) [7] was used as the outcome variable. All 
peaks $(n=147)$ detected on the different surfaces were merged and analyzed together. In addition, each surface was analyzed individually. The peak intensity data were analyzed both directly after pre-processing and after transformation to a logarithmic scale. Serum protein profiles were analyzed before and after 1 year of treatment, and in terms of the change in profiles over 1 year of treatment.

\section{Multivariate statistics}

Multivariate data analysis was performed with Matlab software (version 7.7.0 R2008b, The Mathworks) on the mean intensity levels of the duplicate samples. Cross-validated stepwise regression was computed to find subsets of peaks that correlated with the delta height SDS 0-2 years. Final selection of reliable subsets of predictive peaks was based on a random permutation test. The identified peaks were analyzed thereafter using multidimensional scaling (MDS) to explore the relationships between the peaks.

\section{Between-duplicate variation}

To estimate the reliability of the peaks compared with their biological range, the ratio of the between-duplicate variation and the total variation was computed, giving the proportion of variance explained by duplicates. A low value for a certain peak meant that there was relatively little variation between the duplicates compared with the total expected biological and instrumental variation.

\section{Cross-validated stepwise regression}

Using stepwise regression, subsets of peaks were selected with leave-one-out cross-validation to examine the correlation of the peaks with delta height SDS 0-2 years. Sets of potential regression models were generated using between 1 and a maximum of 15 peaks.

\section{Random permutation tests}

To study the robustness of the data analyses, random permutation tests were performed on the complete stepwise regression procedure described above including the selection of subsets of peaks based on the highest cross-validated $\mathrm{R}^{2}$. For each number of peaks, we tested for 999 permutations if the permuted cross-validated $\mathrm{R}^{2}$ was equal to or above $90 \%$ of the calculated true cross-validated $\mathrm{R}^{2}$. In other words, we assessed if there was a significant gap $(10 \%)$ between the calculated true cross-validated $\mathrm{R}^{2}$ and the distribution of all permuted cross-validated $\mathrm{R}^{2}$. Random permutation tests resulting in a p-value $<0.05$ were considered significant. For each number of peaks, the best regression model was selected based on a significant pvalue in the permutation tests, in combination with a relatively low number of peaks in the regression model and a relative high cross-validated $\mathrm{R}^{2}$.

\section{Analysis of systematic errors}

Stepwise regression was used to analyze the impact of systematic errors on the results. No systematic errors were found.

\section{Results}

\section{Protein expression pattern}

Data from the spectra generated were analyzed both as merged peak data from all analyzed surfaces and in terms of each individual surface. Best results, with respect to the lowest permutation test $\mathrm{p}$-value in combination with high cross-validated $\mathrm{R}^{2}$, were obtained using data from only CM10 on pooled fractions 5 and 6 . All data were analyzed for the GH-deficient group, the ISS group and for the total group.

\section{At start of GH treatment}

In the GH-deficient group of children we identified a specific protein expression pattern of seven peaks that correlated with the delta height SDS $0-2$ years $\left(R^{2}=0.73, p=\right.$ 0.032 ) (Table 2). The correlation between the predicted and the observed delta height SDS $0-2$ years is shown in Figure 1. No significant correlations between the protein expression pattern and the delta height SDS 0-2 years were

Table 2: The most predictive peaks for delta height ${ }_{S D S} 0-2$ year identified by regression analysis

\begin{tabular}{|c|c|c|c|c|c|c|}
\hline Group & Patients $(n=)$ & Peaks $(n=)$ & $\mathbf{R}^{2}$ & Cross-validated $\mathbf{R}^{2}$ & p-value & Peak $\mathrm{m} / \mathrm{z}$ value $(\mathrm{kDa})$ \\
\hline GHD & 39 & 7 & 0,73 & 0,61 & 0,032 & $\begin{array}{l}3.160,3.318,8.767 \text { (Apo A-II), 9.135, 9.642, } 12.872 \text { (TTR), } \\
\text { I7.390 (Apo A-II) }\end{array}$ \\
\hline GHD & 39 & 4 & 0,64 & 0,53 & 0,017 & $\begin{array}{l}4.408 \text { (Aро A-II), } 8.696 \text { (Apo A-II), } 9.019 \text { (Apo A-II) } \\
\text { 17.146 (Aро A-II) }\end{array}$ \\
\hline ISS & 89 & 8 & 0,47 & 0,35 & 0,015 & $\begin{array}{l}\text { 3.160, 4.470, } 6.857 \text { (Apo C-I), } 8.767 \text { (Apo A-II), } 8.875 \text { (Apo A-II), } \\
9.425 \text { (Apo C-III), I 2.607 (SAA4), I 2.872 (TTR) }\end{array}$ \\
\hline Total & 128 & 8 & 0,38 & 0,28 & 0,003 & $4.628,4.470,4.793,8.817,8.875,9.019,12.872,17.146$ \\
\hline GHD & 39 & 4 & 0,59 & 0,48 & 0,026 & 4.I38, 8.817 (Aро A-II), 9.019 (Аро A-II), 17.262 (Аро A-II) \\
\hline Total & 128 & 8 & 0,35 & 0,24 & 0,003 & $\begin{array}{l}\text { 4.138, 8.636 (Apo A-II), } 8.875 \text { (Apo A-II), 9.135, } 9.425 \\
\text { (Apo C-III), I } 4.055 \text { (TTR), } 28.090 \text { (Apo A-I), } 29.003\end{array}$ \\
\hline
\end{tabular}

GHD, GH-deficient; ISS, idiopathic short stature.

The most predictive peaks identified by regression analysis at start, after I year, and during the first year of GH treatment. For each model, the $\mathrm{R}^{2}$ value and cross-validated $\mathrm{R}^{2}$ are presented. 


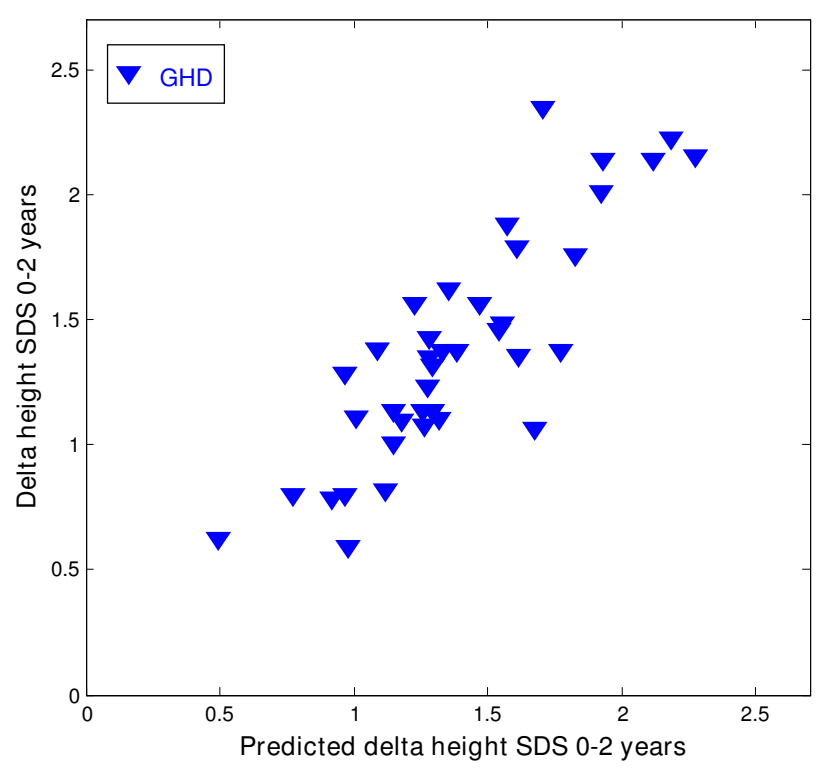

Figure I

Protein peaks at treatment start that were predictive of 2-year growth response in GH-deficient children. The figure shows the correlation between the observed delta height SDS 0--2 year (y-axis) and the predicted delta height SDS 0--2 year (x-axis), using the combined intensities of the predictors with $M / Z$ values --9135, +3318 , + I7390 (Apo A-II), +8767 (Apo A-II), + I 2872 (SAA 4), +9642 (Apo C-III), +3I60 ( $r=0.73, p=0.032)$, in the GHdeficient children (GHD) at start of treatment. A positive sign indicates a positive correlation with the outcome variable whereas a negative sign indicates a negative correlation with the outcome variable.

identified for the total group of patients or the ISS group at start of treatment.

\section{After I year of $\mathrm{GH}$ treatment}

In the GH-deficient group, a protein expression pattern of four peaks correlated with the delta height SDS 0-2 years $\left(\mathrm{R}^{2}=0.64, \mathrm{p}=0.017\right)$ (Table 2, Figure 2A). In the ISS group, a protein expression pattern of eight peaks correlated with the delta height SDS $0-2$ years $\left(\mathrm{R}^{2}=0.47, \mathrm{p}=\right.$ 0.015) (Table 2, Figure 2B). In the total group of children, the expression pattern of eight peaks correlated with the delta height SDS 0-2 years $\left(R^{2}=0.38, p=0.003\right)$ (Table 2, Figure 2C).

\section{During I year of GH treatment}

Finally we assessed correlations between changes in peaks intensities during the first year of GH treatment and the growth response after 2 years of treatment. In the GH-deficient group, the change in expression pattern of four specific peaks correlated with delta height SDS 0-2 years $\left(\mathrm{R}^{2}\right.$ $=0.59, \mathrm{p}=0.026)($ Table 2 , Figure $3 \mathrm{~A})$. There were no sig- nificant correlations found involving the ISS group. For the total group, the change in expression pattern of eight specific peaks correlated with delta height SDS 0-2 years $\left(\mathrm{R}^{2}=0.35, \mathrm{p}=0.003\right)$ (Table 2, Figure $\left.3 \mathrm{~B}\right)$.

\section{Peak identification}

The protein expression patterns that provided the best predictive peaks for the 2-year growth response in the GHdeficient group, the ISS group and the total group, included a total of 23 unique peaks (Table 2). To identify the proteins corresponding to the peaks of interest we used the consistency of the peak pattern in the spectra, MS identification and serum depletion experiments.

\section{Consistency of peak pattern in spectra}

From the consistency of the peak patterns in the spectra, the peaks with $\mathrm{m} / \mathrm{z}$ values around $14 \mathrm{kDa}$ were recognized as different post-translational modified forms of TTR; the $14.055 \mathrm{kDa}$ peak was recognized as the cysteinylated form and the $12.872 \mathrm{kDa}$ peak as a truncated form. The 17.146 , 17.262 and $17.390 \mathrm{kDa}$ peaks were recognized as dimers of Apo A-II, and the 8.636 and $4.408 \mathrm{kDa}$ peaks were recognized as truncated forms of Apo A-II. The 28.090 peak was recognized as Apo A-I.

\section{MS protein identification}

All peaks of interest were analyzed using MS protein identification. MS protein identification verified that the 4.408 and $4.470 \mathrm{kDa}$ peak represented Apo A-II. In addition, the cluster of peaks between 8.636 and 9.019 kDa were identified as Apo A-II. The $6.857 \mathrm{kDa}$ peak was identified as Apo C-I. The MS identification result for the $9.425 \mathrm{kDa}$ peak indicated that this sample was not pure. However, based on the Mascot search result score (score: 2073, number of assigned peptides 51), this peak most likely represented Apo C-III. However Apo A-I was also present in the sample, but with a lower Mascot search result score (score 352, number of assigned peptides 29). The 12.607 $\mathrm{kDa}$ peak was identified as serum amyloid A 4 (SAA 4). The identity of the remaining peaks could not be determined accurately using MS.

\section{Depletion experiments}

To verify the identities obtained from MS analyses of the proteins, depletion experiments using specific antibodies were performed. The depletion experiments using antiApo C-I and anti-Apo C-III antibodies (Abnova, Taipei City, Taiwan) confirmed that the 6.857 peak represented Apo C-I (Figure 4A) and the $9.425 \mathrm{kDa}$ peak represented Apo C-III (Figure 4B). The $14.055 \mathrm{kDa}$ peak has previously been confirmed to represent TTR [13].

\section{Peak intensity changes}

The change in absolute peak intensities during the first year of GH treatment for the Apo A-I, Apo A-II, Apo C-I, 

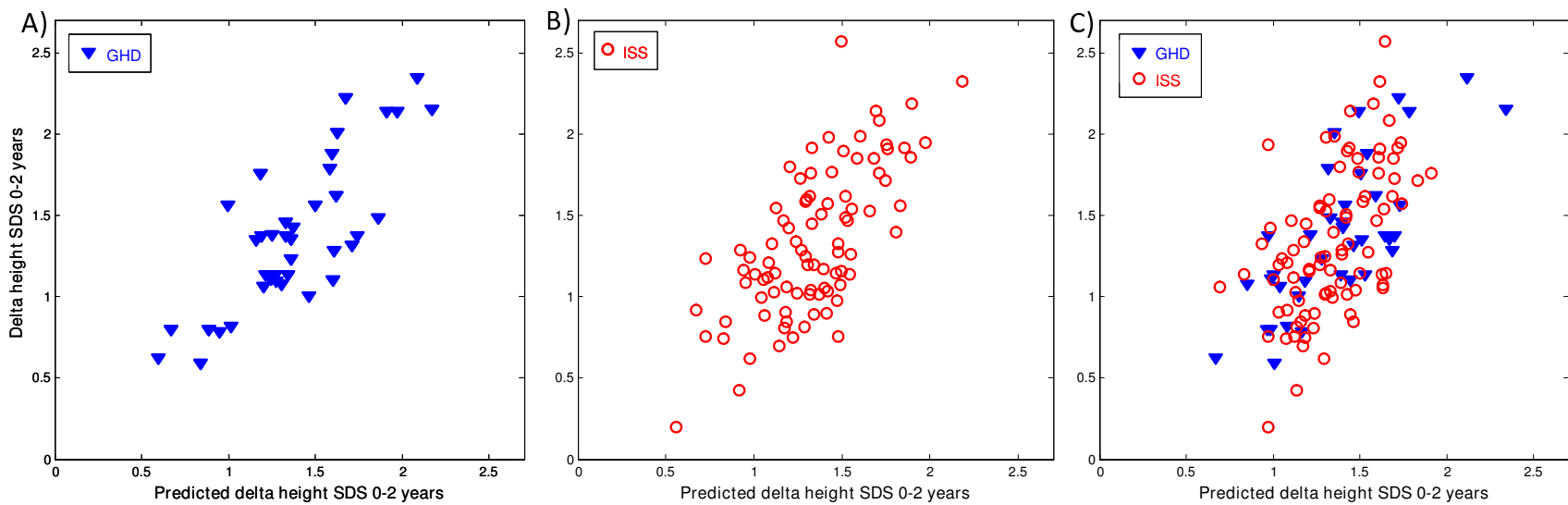

\section{Figure 2}

Protein peaks at I year of treatment that were predictive of 2-year growth response. The figure shows the correlation between the observed delta height SDS 0--2 year (y-axis) and the predicted delta height SDS 0--2 year (x-axis), using the combined intensities of the predictors with M/Z values A) -- I7I46 (Apo A-II), +8696 (Apo A-II), --90 I9 (Apo A-II), +4408 (Apo A-II) $(r=0.64, p=0.017)$. B) +4470 (Apo A-II), --8767 (Apo A-II), --I 2872 (TTR), --I 2607 (SAA 4), +8875 (Apo A-II), +9425 (Apo C-III), --3I60, --6857 (Apo C-I) ( $r=0.47, p=0.015)$. C) --4628, +4470 (Apo A-II), +88I7 (Apo A-II), +4793, --I7I46 (Apo A-II), --I 2872 (TTR), --90I9 (Apo A-II), +8875 (Apo A-II) ( $r=0.38, p=0.003$ ) after I year of treatment in (A) GH-deficient children (GHD), (B) children with idiopathic short stature (ISS), and (C) the total group. A positive sign indicates a positive correlation with the outcome variable whereas a negative sign indicates a negative correlation with the outcome variable.

Apo C-III, TTR and SAA 4 proteins found in this study were fairly small. Apo A-II and SAA4 are significantly decreased $(\mathrm{p}=<0.00001$ and $\mathrm{p}=0.039$, respectively) while Apo C-I and Apo C-III are significantly increased (p $=0.025$ and $\mathrm{p}=0.001$, respectively). Apo A-I and TTR remained unchanged.

\section{Discussion}

In this study we have identified serum protein profiles that correlated with the 2-year growth response to $\mathrm{GH}$ treatment in prepubertal children with GH deficiency and ISS. By using a combination of the specific peak patterns within the spectra, MS identification, and serum depletion experiments, proteins representing a subset of peaks within the profiles were identified. The majority of the proteins identified represent different apolipoproteins; Apo A-I, Apo A-II, Apo C-I and Apo C-III. Other proteins identified were TTR and SAA 4. These results support previous data suggesting that Apo A-II and TTR may have a role in determining GH sensitivity. The change in intensity of these peaks has been shown to allow the classification of children with ISS as good or poor responders to GH treatment [13].

All proteins identified in the current study are part of the HDL [22-24], but Apo A-II, Apo C-I, Apo C-III and SAA 4 have also been found in very low-density lipoproteins and low-density lipoproteins (LDLs) $[24,25]$. HDL is sometimes called 'good' cholesterol as it binds cholesterol and transports it to the liver. It is believed that HDL can remove cholesterol from atheroma within arteries and transport it back to the liver for excretion or re-utilization [26]. Cholesterol contained in HDL particles, unlike cholesterol within LDL particles, is considered beneficial for maintaining cardiovascular health. Today, not much is known about the effects of GH on either the apolipoproteins or on TTR and SAA 4. There are contradictory results regarding the effects of $\mathrm{GH}$ treatment given as daily subcutaneous injection on the HDL which carries these proteins [27-29]. In the present study we found that HDL slightly but significantly decreased during the first year of treatment (data not shown) in contrast to one study that shows increased levels of HDL in only the prepubertal group of boys of whom one third went into puberty during the third year follow-up period [28] Two studies showed almost unchanged levels, one in pubertal GHdeficient patients [27] and one in young adults [29]. In adults, it has been shown that a frequent low GH dose, which gave rise to an almost constant level of plasma GH [30], increased HDL. In contrast, an HDL-lowering effect was seen with a high single GH dose which created a GH plasma profile with an high peak after the GH injection that gradually decreased towards the next daily injection $[29,31]$. This may partly explain the decrease in HDL seen in our study because the children were given a single daily dose of subcutaneous $\mathrm{GH}$ resulting in a plasma pattern of GH with an initial peak and undetectably low levels of GH before next injection [32]. This pattern is more similar to the male GH secretion pattern with a high peak during the night, than the female secretion pattern with uniform GH secretion during both the day and night [33] It is well known that this gender specific secretion pattern is the sig- 

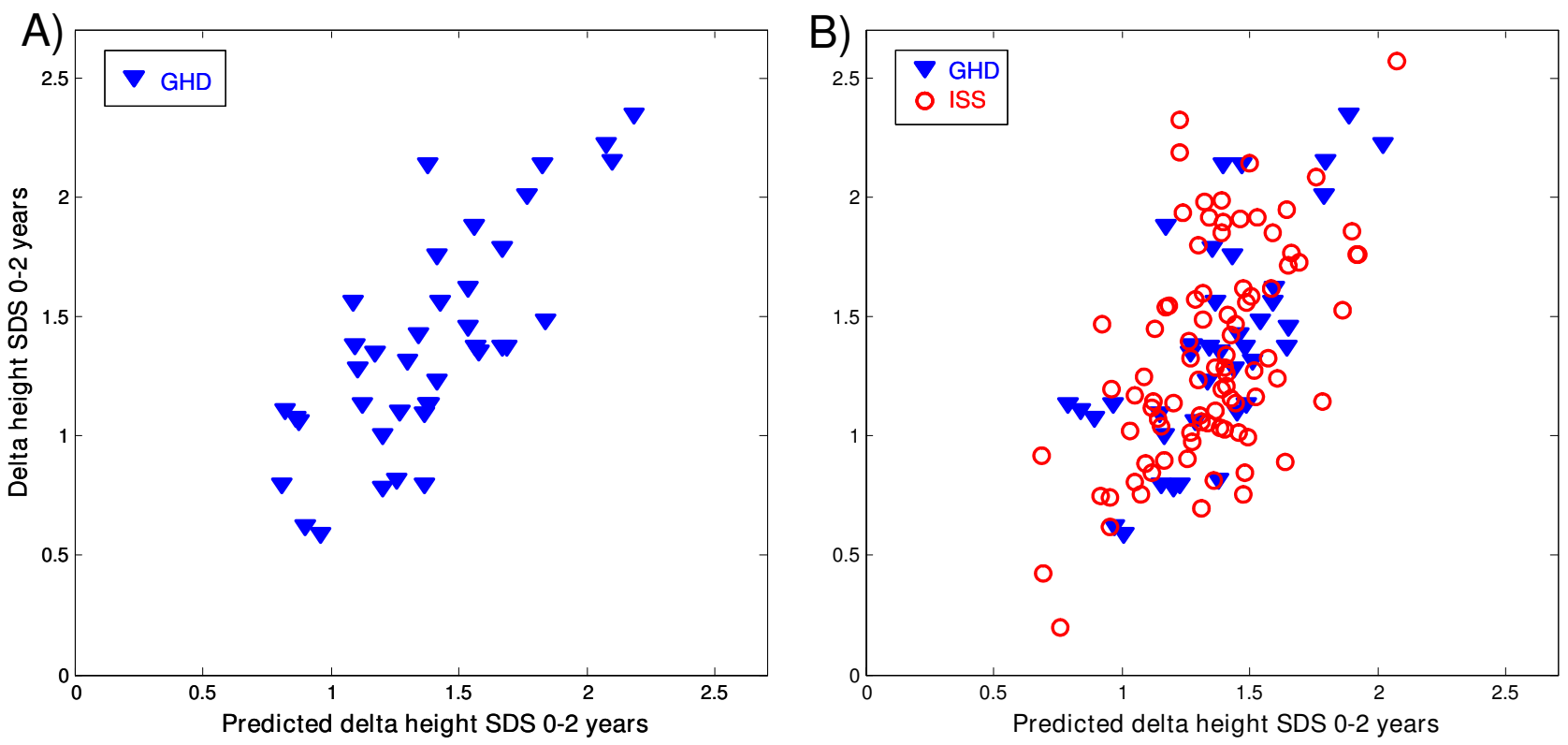

Figure 3

Protein peaks during the first treatment year that were predictive of 2-year growth response. The figure shows the correlation between the observed delta height SDS 0--2 year ( $y$-axis) and the predicted delta height SDS 0--2 year ( $x$-axis) in (A) GH-deficient children (GHD) and (B) the total group, using the combined changes in intensities of the predictors with $M$ / $Z$ values A) +Dy88I7 (Apo A-II), +Dy4I38, --Dy9019, --DyI7262 (Apo A-II) $(r=0.59, p=0.026)$. B) +Dy4I38, --Dy28090 (Apo A-I), +Dyl4055 (TTR), +Dy8875 (Apo A-II), +Dy9I35, +Dy29003, --Dy9425 (Apo C-III), --Dy8636 (Apo A-II) (r = 0.35 , $\mathrm{p}=0.003)$. A positive sign indicates a positive correlation with the outcome variable whereas a negative sign indicates a negative correlation with the outcome variable.

nal for different growth [34] and metabolic effects, not least in the liver, in male and female rats [35,36]. Furthermore, GH affects lipolysis in the body [34] and by doing so probably shifts the energy balance in the body to a more optimal one for longitudinal growth.

From this study it is not possible to draw conclusions as to whether the markers identified are actually involved in the regulation of longitudinal growth or if they are indirect markers of the effects of GH on HDL levels during treatment. The different levels of the identified proteins may be a consequence of the altered levels of HDL and changes in the homeostasis of the lipoproteins. Interpretation of the results is also complicated by the presence of different regulated isoforms and cleavage products of Apo A-II as described in the legends to Figures 1,2 and 3. The physiological significance of the presence of this variety of isoforms/cleavage products should be investigated in future studies.

On the target tissue level one can say that both the GHdeficient and the ISS child are GH-deficient; the deficient one due to low levels of secreted GH, and the idiopathic short child due to GH insensitivity in the target tissue, which often can be overcome by a higher dose of GH treatment [3]. The underlying reason for the tissue insensitivity can vary, giving rise to different phenotypes, whereas the GH-deficient children are of a more similar phenotype. However, there is no clear cut-off for GH secretion between these groups. In this study, different protein patterns were found to correlate with growth in response to treatment for the GH-deficient children and the children with ISS. At the start of treatment, we could only identify specific serum profiles correlating with growth response in the GH-deficient group of patients. There were strong correlations between the 1- and 2-year growth responses in all groups. Interestingly, there was no overlap between the peaks included in the models for the GH-deficient and the ISS groups. In the model for the total group, peaks from both the GH-deficient and the ISS models were found, suggesting that they still have different phenotypes after 1 year of treatment, even if the phenotypes of the two groups have become more similar than they were before the start of GH treatment. Thus, we identified protein profiles correlating with the 2-year growth 

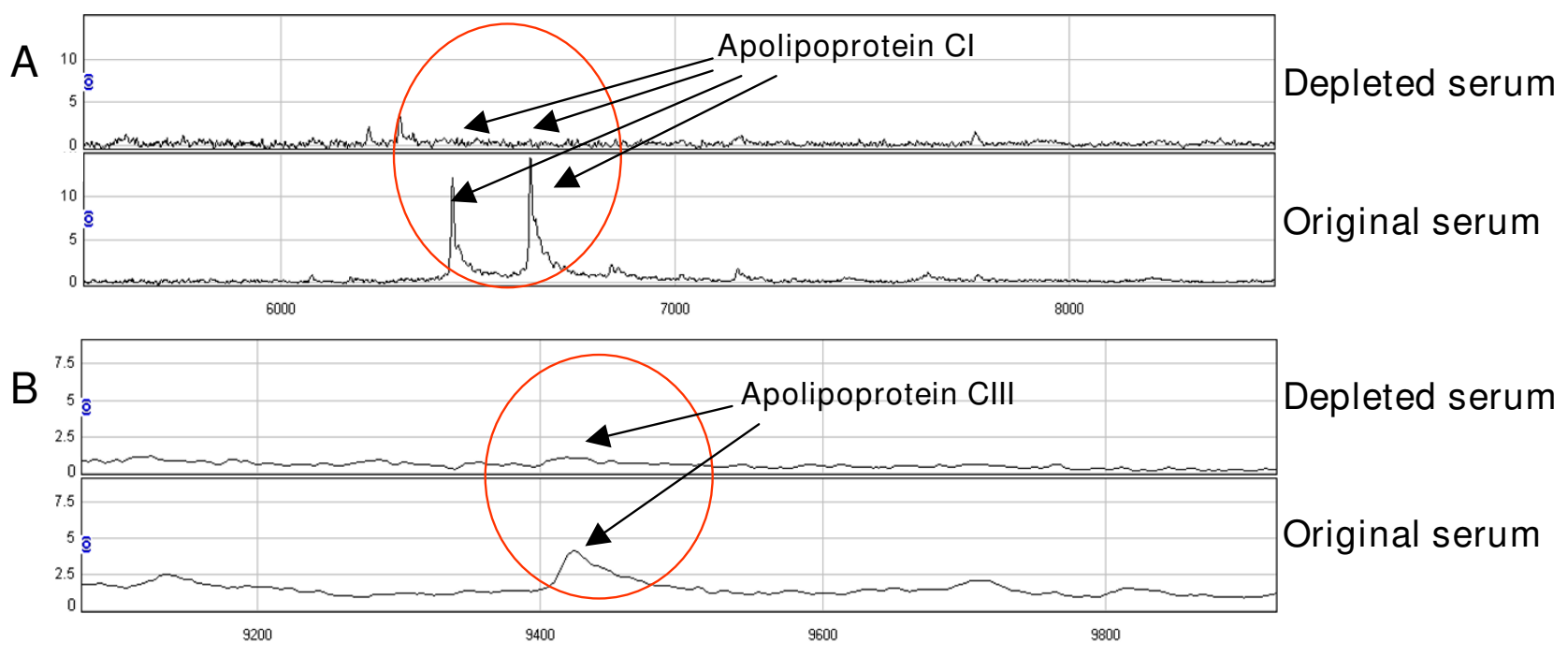

Figure 4

Depletion experiment identifying (A) apolipoprotein C-I, and (B) apolipoprotein C-III. (A) Anti-apolipoprotein C-I antibody depleted the 6.6 and $6.8 \mathrm{kDa}$ peaks. (B) Anti-apolipoprotein C-III antibody depleted the $9.4 \mathrm{kDa}$ peak. In both parts of the figure, the top panel shows the depleted serum and the bottom panel shows the original serum.

response when data from both children with GH deficiency and ISS were included in the analysis.

The optimal time period needed to detect changes in patterns of protein peaks that may be of utility in predicting long term growth is likely to be different for different variables and in different subset of the population. Previously we have shown that growth over the first year of treatment is a good predictor of long-term growth in response to GH (1-7 years) in prepubertal children [12]. However, it would be of interest to analyze protein expression profiles in relation to growth response to treatment after a period shorter than 1 year. SELDI-TOF was recently used to show that the intensity of several peaks was changed in peripheral blood leukocytes from healthy adults after 4 weeks of GH treatment. However for the majority of the peaks the intensities were reverted to baseline levels after additional 4 weeks of treatment and [37].

Currently, the best models for predicting growth in response to GH treatment are based on early growth data, auxological data of the child and the parents, and hormone levels during the pretreatment year $[7,8,11]$. However, the data required by such models are not always readily available. Data on early growth in the child, for example, are seldom available. Similarly, growth during the pre-treatment year and/or information on the height of the parents can not always be obtained. In addition, spontaneous GH profiles may not have been assessed, even though it has been shown that a full $24 \mathrm{~h}$ GH profile is not necessary [38]. These difficulties highlight the need for improved models that are based only on data that is always available at start of therapy.

During the last decade there has been growing interest in proteomics and systems biology in general. A main focus has been exploring the use of new technology to study complex multigenetic diseases, to predict drug response, to individualize treatment and to discriminate between healthy and diseased individuals [39-41]. We have used SELDI-TOF, a high-throughput technique which is suitable for analyzing large numbers of samples, in order to identify specific protein profiles that are correlated with growth in response to treatment, and to get more insight into GH-dependent regulation of longitudinal growth. The challenge in proteomic analyses of serum is the broad range of expression levels between proteins with low and high abundance [42-44]. In order to partly overcome this problem, we used fractionated serum that was analyzed on different array surfaces in order to detect proteins in a larger area of the proteome.

The reproducibility and reliability of the SELDI-TOF proteomic system have been discussed [45-47]. Concerns about using samples from retrospective studies have been raised as transit time, storage conditions, clotting time and tube type can affect protein profiles $[48,49]$. However, proper handling of samples can minimize these shortcomings [50]. Our group has established a welldefined protocol for handling and running of samples in 
proteomic studies [13]. No systematic errors correlated with non-GH-dependent factors or experimental biases such as array or spot number biases were detected. In this study we ran samples on three different surfaces and using three different fractions to cover a larger part of the proteome compared with a single surface and fraction, and in general the most reliable results were found using only the CM10 surfaces. In agreement with other reports, we found a greater number of peaks on the CM10 surface. Moreover, there was a partial overlap between the peaks detected on CM10, IMAC30 and H50, respectively.

Much effort has been put into creating a robust and reliable strategy for the statistical analysis of peak data. Combinations of between-duplicate variation ratio, crossvalidated stepwise regression and random permutation tests were performed in order to make certain that the results obtained were robust and reliable.

\section{Conclusion}

In summary, analysis of serum protein expression patterns can be used to identify markers of growth response in short prepubertal children with either GH-deficiency or ISS receiving GH treatment. Our results support previous findings that apolipoproteins and TTR may have a role in GH sensitivity and could be used to predict growth in response to GH treatment in short prepubertal children. The next step will be to test whether or not the incorporation of information on these peaks (either in addition to or in place of existing variables) in our prediction models for prepubertal growth $[7,8]$ will have an additive predictive value in explaining the response to $\mathrm{GH}$ treatment.

\section{Abbreviations}

AITT: arginine-insulin tolerance test; Apo A-II: apolipoprotein A-II; CV: coefficient of variation; FT/ICR: Fourier transform ion cyclotron; GH: growth hormone; GHD: $\mathrm{GH}$-deficient; $\mathrm{GH}_{\max }$ : maximum peak of $\mathrm{GH}$ secretion; HDL: high-density lipoprotein; IGF-I: insulin-like growth factor I; IGFBP-3: IGF-binding protein 3; ISS: idiopathic short stature; MS: mass spectrometry; LC -MS/MS: liquid chromatography/tandem MS; m/z: mass/charge; LDL: low-density lipoprotein; SDS: standard deviation score; SELDI-TOF-MS: surface-enhanced desorption/ionization time-of-flight mass spectrometry; $\mathrm{S} / \mathrm{N}$ : signal-to-noise ratio.

\section{Competing interests}

KAW declares that she received an unrestricted research grant from Pharmacia/Pfizer until 2005. AFMN works for Muvara, Multivariate Analysis of Industrial and Research Data Statistical Consultation, The Netherlands.

$\mathrm{GH}, \mathrm{BA}$ and $\mathrm{ZH}$ declare that they have no competing interests.

\section{Authors' contributions}

BA, GH, AFMN, ZH and KAW have all given substantial contribution to conception and design, analysis and interpretation of the data. BA, GH and KAW have designed the experiment and BA has carried out all the SELDI-TOF and additional experiments. AFMN performed most of the statistical analyses, the rest have been performed by BA. GH, $\mathrm{BA}, \mathrm{AFMN}, \mathrm{ZH}$ and KAW have all been involved in drafting the manuscript and have revised it critically for intellectual content.

\section{Acknowledgements}

The authors are thankful for fruitful discussions with Peter Iversen and Eva Fernvik at Bio-Rad, and the Sambio core facility at Sahlgrenska Academy at University of Gothenburg for their work. We would also like to thank the team behind the Sparselab software for all the work behind making the software and for making source code public available. The study was supported by a grant from the Lundberg Research foundation for the SELDI-TOF. The investigator-initiated study TRN 98-0198-003 was supported by Pharmacia/ Pfizer. Financial support was also obtained from Swedish Research Council no 7509, Wilhelm \& Martina Lundgrens Foundation, University Hospital (ALF) and West Sweden Region (VGR) grants.

The authors thank the investigators of TRN 98-0198-003: Kerstin Albertsson-Wikland, Stefan Aronson, Berit Kriström, Jovanna Dahlgren, Jan Gustafsson, Maria Halldin, Sten A Ivarsson, Nils-Östen Nilsson, Johan Svensson and Torsten Tuvemo for allowing us to use the data.

\section{References}

I. Albertsson-Wikland K, Rosberg S: Analyses of 24-hour growth hormone profiles in children: relation to growth. The Journal of clinical endocrinology and metabolism 1988, 67(3):493-500.

2. Frasier SD, Costin G, Lippe BM, Aceto T Jr, Bunger PF: A doseresponse curve for human growth hormone. The Journal of clinical endocrinology and metabolism 198I, 53(6): $1213-1217$.

3. Albertsson-Wikland K, Aronson AS, Gustafsson J, Hagenas L, Ivarsson SA, Jonsson B, Kristrom B, Marcus C, Nilsson KO, Ritzen EM, et al.: Dose-dependent effect of growth hormone on final height in children with short stature without growth hormone deficiency. The Journal of clinical endocrinology and metabolism 2008, 93(II):4342-4350.

4. Cohen P, Bright GM, Rogol AD, Kappelgaard AM, Rosenfeld RG: Effects of dose and gender on the growth and growth factor response to $\mathbf{G H}$ in $\mathbf{G H}-d e f i c i e n t$ children: implications for efficacy and safety. The Journal of clinical endocrinology and metabolism 2002, 87(I):90-98.

5. Kristrom B, Aronson AS, Dahlgren J, Gustafsson J, Halldin M, Ivarsson SA, Nilsson NO, Svensson J, Tuvemo T, Albertsson-Wikland K: Growth hormone $(\mathrm{GH})$ dosing during catch-up growth guided by individual responsiveness decreases growth response variability in prepubertal children with $\mathrm{GH}$ deficiency or idiopathic short stature. The Journal of clinical endocrinology and metabolism 2009, 94(2):483-490.

6. Wit JM, Rekers-Mombarg LT, Cutler GB, Crowe B, Beck TJ, Roberts K, Gill A, Chaussain JL, Frisch H, Yturriaga R, et al.: Growth hormone (GH) treatment to final height in children with idiopathic short stature: evidence for a dose effect. The Journal of pediatrics 2005, I 46(I):45-53.

7. Albertsson-Wikland K, Kristrom B, Rosberg S, Svensson B, Nierop AF: Validated multivariate models predicting the growth response to $\mathbf{G H}$ treatment in individual short children with a broad range in $\mathbf{G H}$ secretion capacities. Pediatr Res 2000, 48(4):475-484.

8. Dahlgren J, Kristrom B, Niklasson A, Nierop AF, Rosberg S, Albertsson-Wikland $\mathrm{K}$ : Models predicting the growth response to growth hormone treatment in short children independent of GH status, birth size and gestational age. BMC Med Inform Decis Mak 2007, 7(I):40. 
9. de Ridder MA, Stijnen T, Hokken-Koelega AC: Validation and calibration of the Kabi Pharmacia International Growth Study prediction model for children with idiopathic growth hormone deficiency. The Journal of clinical endocrinology and metabolism 2003, 88(3): I 223-I 227.

10. Land C, Blum WF, Shavrikova E, Kloeckner K, Stabrey A, Schoenau E: Predicting the growth response to growth hormone (GH) treatment in prepubertal and pubertal children with isolated GH deficiency--model validation in an observational setting (GeNeSIS). J Pediatr Endocrinol Metab 2007, 20(6):685-693.

II. Ranke MB, Lindberg A, Chatelain P, Wilton P, Cutfield W, Albertsson-Wikland K. Price DA: Derivation and validation of a mathematical model for predicting the response to exogenous recombinant human growth hormone $(\mathrm{GH})$ in prepubertal children with idiopathic GH deficiency. KIGS International Board. Kabi Pharmacia International Growth Study. The Journal of clinical endocrinology and metabolism 1999, 84(4): I I74-I I83.

12. Kristrom B, Dahlgren J, Niklasson A, Nierop AF, Albertsson-Wikland $\mathrm{K}$ : The first-year growth response to growth hormone treatment predicts the long-term prepubertal growth response in children. BMC Med Inform Decis Mak 2009, 9:1.

13. Hellgren G, Andersson B, Nierop AF, Dahlgren J, Hochberg Z, Albertsson-Wikland K: A proteomic approach identified growth hormone dependent nutrition markers in children with idiopathic short stature. Proteome science 2008, 6(I):35.

14. Jansson C, Boguszewski C, Rosberg S, Carlsson L, Albertsson-Wikland K: Growth hormone (GH) assays: influence of standard preparations, $\mathbf{G H}$ isoforms, assay characteristics, and $\mathbf{G H}$ binding protein. Clin Chem 1997, 43(6 Pt I):950-956.

15. Lofqvist C, Andersson E, Gelander L, Rosberg S, Blum WF, Albertsson Wikland K: Reference values for IGF-I throughout childhood and adolescence: a model that accounts simultaneously for the effect of gender, age, and puberty. The Journal of clinical endocrinology and metabolism 200I, 86( I 2):5870-5876.

16. Lofqvist C, Andersson E, Gelander L, Rosberg S, Hulthen L, Blum WF, Wikland KA: Reference values for insulin-like growth factorbinding protein-3 (IGFBP-3) and the ratio of insulin-like growth factor-I to IGFBP-3 throughout childhood and adolescence. The Journal of clinical endocrinology and metabolism 2005 , 90(3): $1420-1427$.

17. Karlberg J: On the construction of the infancy-childhoodpuberty growth standard. Acta Paediatr Scand Suppl 1989, 356:26-37.

18. Albertsson-Wikland K, Luo ZC, Niklasson A, Karlberg J: Swedish population-based longitudinal reference values from birth to 18 years of age for height, weight and head circumference. Acta Paediatr 2002, 9 I (7):739-754.

19. Karlberg J, Luo ZC, Albertsson-Wikland K: Body mass index reference values (mean and SD) for Swedish children. Acta Paediatr 200I, 90( I 2): | 427-| 434

20. Niklasson A, Ericson A, Fryer JG, Karlberg J, Lawrence C, Karlberg P: An update of the Swedish reference standards for weight, length and head circumference at birth for given gestational age (1977-198I). Acta Paediatr Scand I99I, 80(8-9):756-762.

21. Kay R, Barton C, Ratcliffe L, Matharoo-Ball B, Brown P, Roberts Teale P, Creaser C: Enrichment of low molecular weight serum proteins using acetonitrile precipitation for mass spectrom etry based proteomic analysis. Rapid Commun Mass Spectrom 2008, 22(20):3255-3260.

22. Shachter NS: Apolipoproteins C-I and C-III as important modulators of lipoprotein metabolism. Current opinion in lipidology 200I, I 2(3):297-304.

23. Sousa MM, Berglund L, Saraiva MJ: Transthyretin in high density lipoproteins: association with apolipoprotein A-I. Journal of lipid research 2000, 4 I (I):58-65.

24. Yamada T, Miida T, Itoh Y, Kawai T, Benson MD: Characterization of serum amyloid A4 as a plasma apolipoprotein. Clinica chimica acta; international journal of clinical chemistry 1996, 25 I ( I): 1 05- I I 2

25. Allard L, Lescuyer P, Burgess J, Leung KY, Ward M, Walter N, Burkhard PR, Corthals G, Hochstrasser DF, Sanchez JC: ApoC-I and ApoC-III as potential plasmatic markers to distinguish between ischemic and hemorrhagic stroke. Proteomics 2004, 4(8):2242-2251.
26. Florentin M, Liberopoulos EN, Wierzbicki AS, Mikhailidis DP: Multiple actions of high-density lipoprotein. Current opinion in cardiology 2008, 23(4):370-378.

27. Hilczer M, Smyczynska J, Stawerska R, Lewinski A: Effects of oneyear low-dose growth hormone (GH) therapy on body composition, lipid profile and carbohydrate metabolism in young adults with childhood-onset severe GH deficiency confirmed after completion of growth promotion. Endokrynologia Polska 2008, 59(4):292-300.

28. Kuromaru R, Kohno H, Ueyama N, Hassan HM, Honda S, Hara T: Long-term prospective study of body composition and lipid profiles during and after growth hormone (GH) treatment in children with GH deficiency: gender-specific metabolic effects. The Journal of clinical endocrinology and metabolism 1998, 83( I I):3890-3896.

29. Lanes R, Soros A, Gunczler P, Paoli M, Carrillo E, Villaroel O, Palacios A: Growth hormone deficiency, low levels of adiponectin, and unfavorable plasma lipid and lipoproteins. The Journal of pediatrics 2006, I49(3):324-329.

30. Robinson IC: The growth hormone secretory pattern: a response to neuroendocrine signals. Acta Paediatr Scand Suppl 1991, 372:70-78. discussion 79-80.

31. Robinson IC, Gevers EF, Bennett PA: Sex differences in growth hormone secretion and action in the rat. Growth Horm IGF Res 1998, 8(Suppl B):39-47.

32. Albertsson-Wikland K, Westphal O, Westgren U: Daily subcutaneous administration of human growth hormone in growth hormone deficient children. Acta Paediatr Scand 1986, 75(I):89-97.

33. Jaffe CA, Ocampo-Lim B, Guo W, Krueger K, Sugahara I, DeMottFriberg R, Bermann M, Barkan AL: Regulatory mechanisms of growth hormone secretion are sexually dimorphic. J Clin lnvest 1998, 102(I): 153-164.

34. Nam SY, Marcus C: Growth hormone and adipocyte function in obesity. Horm Res 2000, 53(Suppl I):87-97.

35. Mode A, Ahlgren R, Lahuna O, Gustafsson JA: Gender differences in rat hepatic CYP2C gene expression--regulation by growth hormone. Growth Horm IGF Res 1998, 8(Suppl B):6I-67.

36. Waxman DJ, O'Connor C: Growth hormone regulation of sexdependent liver gene expression. Molecular endocrinology (Baltimore, Md) 2006, 20(I I):2613-2629.

37. Chung L, Nelson AE, Ho KK, Baxter RC: Proteomic profiling of growth hormone-responsive proteins in human peripheral blood leukocytes. The Journal of clinical endocrinology and metabolism 2009, 94(8):3038-3043.

38. Kristrom B, Lofqvist C, Rosberg S, Albertsson Wikland K: Effect of spontaneous $\mathbf{G H}$ secretion and the $\mathbf{G H}$ sampling period on the accuracy of models for predicting growth responses to GH treatment. The Journal of clinical endocrinology and metabolism 200I, 86(I 0):4963-4964.

39. Daly AK: Individualized drug therapy. Current opinion in drug discovery \& development 2007, I0(I):29-36.

40. Rosenfeld RG: Pharmacogenomics and pharmacoproteomics in the evaluation and management of short stature. Eur J Endocrinol 2007, I57(SuppI I):S27-3I.

4I. Weber WW: Pharmacogenetic tactics and strategies: implications for paediatrics. Paediatric drugs 200I, 3( I 2):863-88 I

42. Anderson NL, Anderson NG: The human plasma proteome: history, character, and diagnostic prospects. Mol Cell Proteomics 2002, I (I I):845-867.

43. Corthals GL, Wasinger VC, Hochstrasser DF, Sanchez JC: The dynamic range of protein expression: a challenge for proteomic research. Electrophoresis 2000, 2 I (6): I I04-III5.

44. Thadikkaran L, Siegenthaler MA, Crettaz D, Queloz PA, Schneider P, Tissot JD: Recent advances in blood-related proteomics. Proteomics 2005, 5( I 2):3019-3034.

45. Baggerly KA, Morris JS, Edmonson SR, Coombes KR: Signal in noise: evaluating reported reproducibility of serum proteomic tests for ovarian cancer. Journal of the National Cancer Institute 2005, 97(4):307-309.

46. Diamandis EP: Mass spectrometry as a diagnostic and a cancer biomarker discovery tool: opportunities and potential limitations. Mol Cell Proteomics 2004, 3(4):367-378.

47. Diamandis EP: Serum proteomic profiling by matrix-assisted laser desorption-ionization time-of-flight mass spectrome- 
try for cancer diagnosis: next steps. Cancer Res 2006, 66(II):5540-554I.

48. Coombes KR, Morris JS, Hu J, Edmonson SR, Baggerly KA: Serum proteomics profiling--a young technology begins to mature. Nat Biotechnol 2005, 23(3):291-292.

49. Karsan A, Eigl B], Flibotte S, Gelmon K, Switzer P, Hassell P, Harrison D, Law J, Hayes M, Stillwell M, et al.: Analytical and preanalytical biases in serum proteomic pattern analysis for breast cancer diagnosis. Clin Chem 2005, 5 I (8): I525-I528.

50. Timms JF, Arslan-Low E, Gentry-Maharaj A, Luo Z, T'Jampens D, Podust VN, Ford J, Fung ET, Gammerman A, Jacobs I, et al.: Preanalytic influence of sample handling on SELDI-TOF serum protein profiles. Clin Chem 2007, 53(4):645-656.

Publish with Bio Med Central and every scientist can read your work free of charge

"BioMed Central will be the most significant development for disseminating the results of biomedical research in our lifetime. "

Sir Paul Nurse, Cancer Research UK

Your research papers will be:

- available free of charge to the entire biomedical community

- peer reviewed and published immediately upon acceptance

- cited in PubMed and archived on PubMed Central

- yours - you keep the copyright

Submit your manuscript here:

http://www.biomedcentral.com/info/publishing_adv.asp
BioMedcentral 